\title{
Phase I study of sorafenib combined with radiation therapy and temozolomide as first-line treatment of high-grade glioma
}

A F Hottinger, A Ben Aissa, V Espeli, D Squiban, N Dunkel, M I Vargas, T Hundsberger, N Mach, K Schaller, D C Weber, A Bodmer and P-Y Dietrich

Correction to: British Journal of Cancer (2014) 110, 2655-2661. doi:10.1038/bjc.2014.209; published online 1 May 2014

Following the publication of this manuscript, it was recognised that an author name had been provided incorrectly. The correct name is A Ben Aissa. This name is now given in the author list above.
This work is published under the BJC's standard license to publish agreement. After 12 months the license terms will change to a Creative Commons AttributionNonCommercial-Share Alike 4.0 Unported License. 